\title{
Porque Devemos, de Novo, Erradicar o Aedes Aegypti
}

\author{
Maria da Glória Teixeira ${ }^{1}$ \\ Maurício Lima Barreto ${ }^{1}$
}

\begin{abstract}
Resumo: A ocorrência de epidemias de Dengue Clássica, Febre Hemorrágica da Dengue e Síndrome de Choque da Dengue, no Brasil e nas Américas, faz com que essa virose se constitua em um dos grandes problemas de saúde pública do continente, o que impõe uma reflexão sobre sua situação epidemiológica e as estratégias de seu enfrentamento. Neste sentido, um importante debate nacional vem se processando, desde o início do ano de 1995 sobre a estratégia de prevenção que deve ser adotada no Brasil. O Conselho Nacional de Saúde ao criar uma Comissão Técnica para analisar o problema não descartou a readoção de uma proposta de erradicação do Aedes Aegypti, estratégia adotada até 1985, quando foi substituída por um programa de controle. Seminário promovido pelo Conselho Nacional de Saúde e Ministério da Saúde em novembro de 1995, com a participação da comunidade científica (ABRASCO, SBMT e SBP), CONASS, CONASSEMS e de profissionais de saúde que desenvolvem trabalho nesta área, revelou a existência de opiniōes favoráveis e desfavoráveis à erradicação do Aedes aegypti. Este artigo sistematiza esta discussão, e a opiniào dos autores é de que, levando em consideração as diretrizes técnicas e políticas imprimidas ao Plano Nacional de Erradicaçào do Aedes aegypti do Brasil, emanaủas do Conselho Nacional de Saúde e referendadas pelos participantes do Seminário, os profissionais de saúde e a sociedade brasileira devem lutar pela efetiva implantação do referido Plano. Isso porque, apesar de todas as questòes técnicas envolvidas, o plano além de factível é defensável pelos seus aspectos humanos, éticos e pela capacidade de resgatar questōes essenciais como o próprio Sistema único de Saúde e a luta pela eqüidade social e inter-regional no país.
\end{abstract}

Palavras-chave: Dengue Clássica, Febre Hemorrágica da Dengue e Síndrome de Choque da Dengue; Plano Nacional de Erradicação; Dengue no Brasil e nas Américas.

Summary: The occurrence of epidemics of Classic Dengue, Dengue Hemorragic Fever and Dengue Shock Syndrome in Brazil and other American countries highlight the fact that those viroses constitute an important public health problem in the continent and stress the need of a permanent evaluation of its epidemiological picture and the development of preventive strategies. Since 1995, an important national debate came out on the strategy of prevention that must be adopted in Brazil. The National Health Council (CNS) created a task force to analyze the problem, that renewed the thesis of erradication of the Aedes aegypti. Erradication was the strategy employed until 1985, when it was replaced by a control approach. A Seminar

1 Instituto de Saúde Coletiva, Universidade Federal da Bahia (UFBa), Salvador, Bahia. 
promoted by CNS in November, 1995, with the participation of members of scientific community, representatives of the State and Municipal Health Secretaries Councils, and health professionals from different public offices disclosed the existence of favorable and unfavorable opinions as far as Aedes aegypti erradication is concerned. This article aims to present a summary of such discussion. The authors endorse the "Aedes aegypti National Erradication Plan" that emerged from CNS Seminar. Despite its technical and scientific problems the plan is feasible, defensible by its capacity to reintroduce essential questions such as the original aims of the Unified Health System (SUS), and the struggle for a better social and inter-regional equity in the country.

\section{Introdução}

O Brasil vem convivendo com epidemias de dengue desde o ano de 1981. A presença do Aedes aegypti em grande parte do território nacional e a existência de grandes contingentes populacionais com os requisitos imunológicos para desenvolver formas severas da doença estabelecem condições epidemiológicas necessárias para a eclosão de surtos de dengue em que formas hemorrágicas e outras apresentações severas da doença podem constituir proporções importantes do total de casos. Desde 1990, constatou-se a circulação em nosso meio de dois sorotipos do vírus (DEN-1 e DEN-2), com a ocorrência de casos de dengue hemorrágico, inclusive levando a óbitos. Até bem recentemente, a abordagem desse problema limitava-se às instituições de saúde responsáveis pelo controle do vetor e aos círculos acadêmicos. Frente à gravidade da situação, o Conselho Nacional de Saúde iniciou uma ampla discussão sobre a questão, na perspectiva da adoção de medidas mais enérgicas de prevenção. Este debate tem sido rico e inovador, na medida em uma doença epidêmica passou a ser entendida, não mais como um problema restrito às instituições de saúde, mas como um problema a ser enfrentado por toda a sociedade. Desde o início, ficou claro que a solução desejada impõe ações que ultrapassam o combate químico ao vetor, passando por propostas mais abrangentes sobre os determinantes da sua existência e proliferação, e que deveriam estar inseridas no processo de luta pela descentralização das ações de saúde e pela melhoria da qualidade de vida da população brasileira. Neste artigo, busca-se sumarizar essas discussões e defender a tese de que a proposta de erradicação do Aedes aegypti, nascida no âmbito deste debate, e a despeito de todas as questões técnicas envolvidas, é não só factível como defensável pelos seus aspectos humanos, éticos e pela capacidade de resgatar questões essenciais, como o próprio Sistema Único de Saúde e a luta pela eqüidade social e inter-regional.

\section{O Aedes aegypti e a Dengue}

A Febre Amarela e a Dengue são viroses que embora tenham manifestações clínicas e respostas imunológicas bastante diferenciadas, epiclemiologicamente se entrelaçam, em virtude de apresentarem no seu ciclo um vetor comum que é o Aedes aegrpti. Possivelmente, este foi introduzido nas Américas no início da sua colonização, proveniente do continente africano (Francisco, 1983; Brés, 1986). Desta forma, a ocorrência destas viroses está intimamente relacionada à distribuição e dispersão deste mosquito e às formas como o mesmo foi combatido ao longo do tempo. Isso significa que a história da erradicação da Febre Amarela urbana nas Américas contribuiu significativamente para diminuir, ou mesmo impedir, a circulação dos vírus da Dengue no continente até a década de 1960. 
Até bem recentemente, nenhum país do continente americano desenvolvia programas de prevenção especificamente voltados contra a Dengue. Todos os esforços de controle ou de erradicação do Aedes aegypti tinham a perspectiva de impedir a reurbanização da Febre Amarela. No Brasil, a primeira campanha sanitária instituícla contra a Febre Amarela data de 1690, quatro anos após o início de uma epidemia no Recife, a qual teve sua origem em São Domingos, nas Antilhas (Franco, 1976). Deve-se notar que, nesta época, não se conhecia o ciclo epidemiológico da doença e o fato de que a mesma fosse transmitida por um vetor. Predominavam as concepçôes miasmáticas, e as medidas de controle recomendavam a purificação do ar, através da queima de ervas cheirosas, de tiros de artilharia, da caiação das casas onde havia mortos e da limpeza das ruas. Estas recomendações, apesar de não estarem fundamentadas no conhecimento da transmissão vetorial, tinham a potencialidade de reduzir a população de mosquitos e o número de criaclouros. Apesar disso, esta primeira epidemia persistiu por mais de dez anos.

Apenas em 1881, Carlos J. Finlay relacionou o Aedes aegypti à transmissão da Febre Amarela (Rodríguez Exposito, 1971). Em 1906, Bancroft publicou as primeiras evidências de que o Aedes aegypti estava também relacionado à transmissão da dengue. Em 1908, estes achados foram confirmados por Agromonte e outros autores (Centers for Disease Control, 1979).

Essas informações forneceram o suporte técnico-científico para o desenho das campanhas de combate à Febre Amarela do início do século. No Brasil, as primeiras campanhas foram instituídas por Emílio Ribas, nas cidades de Sorocaba, em 1901; São Simão, 1902 e Ribeirão Preto, 1903. A base da campanha era a eliminação dos focos de mosquitos, com a remoção das latas vazias, cacos de garrafas e outros receptáculos que pudessem servir para a proliferação do vetor; e envolvia, ain- da, a extinção dos capinzais no perímetro urbano e o "expurgo" dos pacientes dos cômodos das suas casas. Estes eram internados ou, alternativamente, isolados em seus domicílios, através do uso de cortinados em torno de seus leitos (Franco, 1976).

Em abril de 1903, Oswaldo Cruz iniciou a talvez mais famosa campanha contra a Febre Amarela, na cidade do Rio de Janeiro, cujas bases eram: evitar que os mosquitos se infectassem ao picar os doentes (isolamento) e impedir a proliferação dos mesmos. O sanitarista chamava a atenção para o fato de que o efeito da campanha dependia da não-interrupção dessas atividades. Para isso, lançou mão de instrumentos jurídicos coercitivos "... que tornem efetivas as disposições regulamentares já existentes sobre a notificação compulsória, estabelecendo medidas repressivas contra os sonegadores de doentes." (Franco, 1976, p. 77). Oswaldo Cruz alicerçou-se no conhecimento técnico-científico recém- adquirido na época para desenhar sua campanha e, ao mesmo tempo, lançou mão do aparato repressivo, de modo a garantir que as ações fossem postas em prática, independentemente da opinião popular. Isto gerou importante reação da classe política e da populaçào, incluindo levantes violentos (Costa, 1985). Ainda assim, a campanha conseguiu finalmente eliminar a Febre Amarela do Rio de Janeiro, no ano de 1909.

Após as experiências de São Paulo e Rio de Janeiro, várias outras cidades brasileiras realizaram campanhas semelhantes contra a Febre Amarela. Em 1940, o responsável pelo Serviço de Controle da Febre Amarela em Recife, iniciou um trabalho que denominou de "Marcha para a Erradicação do Aedes aegvpti", no qual inspecionava e tratava 100\% dos domicílios dos municípios infestados (Ruanet, 1940). Os resultados deste trabalho levaram o Governo Brasileiro a estabelecer a meta de erradicação para o vetor através do Decreto № 8645, de 4 de fevereiro de 1942. Pela primeira vez, admitiu-se a erradicação 
do Aedes aegypti em caráter oficial. O trabalho que o Brasil desenvolveu foi reconhecido internacionalmente e a experiência absorvida por outros países americanos (OPAS, 1942). Em 1947, o Brasil solicitou ao Conselho Diretor da OPAS a erradicação do Aedes aegypti em todo o continente americano. A solicitação foi acatada (OPAS, 1947), sendo iniciada campanha de âmbito continental. Neste mesmo período, teve início a utilização do primeiro inseticida de ação residual, o DDT, no combate ao vetor (Franco, 1976), o que determinou um grande impacto no conjunto das lutas antivetoriais.

A Campanha de Erradicação Brasileira cobriu praticamente todo o território nacional, tendo atingido 1882 dos 1894 municípios então existentes. O mosquito foi identificado em 1187 municípios, ou seja, 63\% do total. Só foram excluídos 12 municípios, por estarem situados na selva amazônica e por acreditarse que lá o vetor não seria encontrado (Franco, 1976). A campanha de erradicação debelou o último foco do mosquito no ano de 1955, em Santa Terezinha, município baiano. Em 1958, o certificado de erradicação foi outorgado ao Brasil e dez outras nações americanas (OPAS, 1958), e, posteriormente, a outros países do continente (OPAS, 1960, 1961, 1963, 1965).

Entretanto, o fato de muitos países do continente não terem desenvolvido o esforço de erradicação possibilitou, somado a outras causas, que o mosquito fosse reintroduzido, não só no Brasil, como em outros países que também o haviam erradicado. Hoje quase todos os países do hemisfério já se reinfestaram, exceção feita a Bermuda, Canadá, Chile e Uruguai (Nelson, 1996). Assim, em 1967 e 1969, constatou-se a presença do vetor na cidade de Belém, e as medidas de controle deste foco fizeram com que a cidade estivesse novamente livre do Aedes aegypti em 1973 e que o mesmo não se dispersasse para outros locais (Amaral, 1983; Marques, 1985).
Em 1976, o Aedes aegrpti foi novamente identificado no país, na área portuária de Salvador (Amaral, 1983; MS/FNS, 1996). Em seguida, foram observados outros focos no Rio de Janeiro e diversas cidades brasileiras (Amaral, 1983). A epidemia de Dengue em Boa Vista (Roraima), em 1981, surpreendeu as autoridades sanitárias brasileiras, uma vez que nào se suspeitava da presença do mosquito naquela área (Osanai, 1984). Logo após, em 1986, explode a epidemia no Rio de Janeiro, e a partir daí o Aedes aegypti rapidamente se dispersa por extensas áreas do território nacional. Atualmente, o vetor já foi identificado em pelo menos 1754 municípios, distribuídos em 18 Unidades Federadas. Estes dados dizem respeito apenas às áreas cobertas pelas atividades da Fundação Nacional de Saúde, significando que um número ainda maior de municípios pode estar infestado (MS/ FNS, 1986).

\section{Dengue nas Américas}

O vírus da Dengue foi isolado pela primeira vez na década de 50 . Antes desta épo$\mathrm{ca}$, os registros de casos ou de epidemias baseavam-se em critérios clínico-epidemiológicos. Sabe-se que muitas são as infecções capazes de produzir sinais e sintomas típicos da Dengue, os quais incluem febre, cefaléia, mialgias e exantemas. No entanto, a Dengue é a única infecção capaz de se apresentar sob a forma de epidemias explosivas, que se correlacionam com a dispersão e a densidade do Aedes aegypti. Esta característica súbita e maciça possibilitou, com alguma segurança, a caracterização e descrição de algumas epidemias de dengue, antes mesmo do conhecimento do vírus e da disponibilidade dos diagnósticos virológico e sorológico (Ehrenkranz, 1971).

Considera-se que as primeiras epidemias de dengue, registradas na literatura, tenham ocorrido na ilha de Java (Jakarta) e no Egito, 
ambas em 1779, e em Filadélfia (EUA), no ano seguinte (Torre, 1990). Ao longo dos três últimos séculos, tem-se registrado a ocorrência de Dengue em várias partes do mundo, com pandemias e epidemias isoladas, atingindo as Américas, a África, a Ásia, a Europa e a Austrália.

Por um longo período, essa virose foi considerada uma doença benigna e, somente após a Segunda Guerra Mundial ocorreram surtos de uma febre hemorrágica severa que, posteriormente, seria identificada como uma forma da Dengue. O primeiro desses eventos, descrito nas Filipinas, em 1953, foi confundido com a Febre Amarela e com outras arboviroses do grupo B. Só posteriormente, em 1958, com a epidemia de Bangkok (Tailândia), esta febre hemorrágica foi descrita como Dengue. Entretanto, através do diagnóstico retrospectivo, aceita-se hoje que a primeira epidemia de Dengue Hemorrágica tenha ocorrido na Grécia, em 1927/1928, alcançando incidencia alarmante e alta letalidade. A investigação de soros de sobreviventes indicou a circulação dos vírus DEN-1 e DEN-2 (Papangelou \& Halstead, 1977; Halstead \& Papangelou, 1980). Outros países do sudeste asiático vêm apresentando a Dengue Hemorrágica, incluindo o Vietnà do Sul (1960), Singapura (1962), Malásia (1963), Indonésia (1969) e Birmânia (1970). Nesta região, sob a forma epidêmica ou endêmica, milhares de casos e de óbitos ocorrem a cada ano, predominantemente em crianças. Essa apresentação clínica tem sido associada à circulação dos vírus de tipos 1, 2 e 3.

Nas Américas, o vírus da Dengue circulou desde o século passado até as primeiras décadas do atual. Em seguida, houve um silêncio epidemiológico, e considera-se que a sua reintroduçào teria ocorrido nos anos 60 (sorotipos 2 e 3), associando-se à ocorrência de várias epidemias de Dengue Clássica. Em 1963, registraram-se os primeiros casos de Dengue na Jamaica (DEN-3), os quais proliferaram na Martinica, em Curaçau, na Antigua, em Saint Kitts, em Sanguilla, na Venezuela e em Porto Rico; logo após, a doença atinge o Norte da América do Sul (Venezuela e Colômbia) e casos importados são notificados nos EUA (Donalísio, 1995). Entre 1968 e 1970, epiclemias causadas pelos vírus tipos 2 e 3 foram registradas no Caribe, na Guiana Francesa e na Venezuela. Na década de 70 , também ocorreram epidemias na Colômbia, em Porto Rico e em Saint Thomas, com isolamento dos mesmos vírus. Em 1977, o vírus sorotipo 1 é introduzido na Jamaica e se dissemina em todas as ilhas do Caribe e na América Tropical. Entre esse ano e 1980 foram notificados 702 mil casos de Dengue Clássica nas Américas, quase todos pelo vírus sorotipo 1 (OPAS, 1995a).

A década de 80 se destaca pelo aumento da circulação dos vírus causadores da dengue no continente americano. Os países que mais notificaram casos foram: Brasil, Colombia, Guatemala, Honduras, México, Nicarágua, Paraguai, Porto Rico e Venezuela. Também no início desta década, foi isolado o vírus DEN-4. Os primeiros casos de Dengue Hemorrágica nas Américas ocorreram em Curaçau e na Venezuela na década de 60 , e em Honduras, Jamaica e Porto Rico, nos anos 70 , com poucas confirmações laboratoriais (OPAS, 1995a).

$\mathrm{O}$ acontecimento epidemiológico mais relevante na história da Dengue nas Américas foi a epidemia de Dengue Hemorrágica e Síndrome de Choque da Dengue (DH/SCD), ocorrida em Cuba, no ano de 1981 . Foram notificados 344203 casos, com 116143 hospitalizaçốes. Foram considerados graves 10312 casos, e 158 resultaram em óbitos, dos quais 101 em crianças (Kouri, 1986; OPAS, 1995a). O vírus associado a essa epidemia foi subtipado como DEN-2, epidemia esta precedida por outra causada pelo vírus DEN-1.

Em outubro de 1989, eclodiu na Venezuela um surto de DH/SCD, com um total de 8619 casos e 117 óbitos. Foram isolados os vírus dos subtipos DEN-1, DEN-2 e DEN-4. Dois 
terços dos casos foram registrados em menores de 14 anos. Este episódio é considerado o segundo mais grave nas Américas. Desde 1981, têm ocorrido, sistematicamente, casos de Dengue Hemorrágica no continente americano, registrando-se, até 1995, 37030 casos, com 526 óbitos, o que corresponde a uma letalidade de $1,5 \%$. O país que mais contribuiu para este total foi a Venezuela (20490 casos), seguido de Cuba, Nicarágua, Colômbia e Brasil (Pinheiro, 1996).

Nos anos 90, o quadro epiclemiológico das Américas e do Cạribe se agravou. Os quatro sorotipos do vírus passaram a circular amplamente, e epidemias de Dengue Clássica têm sido freqüentemente observadas em vários centros urbanos, muitas delas associadas à ocorrência de casos de Dengue Hemorrágica. Em algumas áreas, a virose já se apresenta sob forma endêmica.

\section{Dengue e Febre Amarela no Brasil}

Os primeiros registros de casos de Dengue no Brasil datam de 1916, em São Paulo, e de 1923, em Niterói. Neste último ano, um navio francês aportou em Salvador (Bahia) com casos suspeitos, porém não foram registrados casos autóctones na cidade (Soares, 1928). Um inquérito sorológico realizado na Amazônia em 1953/1954 encontrou soropositividade para a Dengue, sugerindo que o vírus havia circulado na região (Causey \& Theiler, 1962).

No país, a primeira epidemia de dengue confirmada clinica e laboratorialmente teve lugar em 1981, em Boa Vista (Roraima) (Osanai, 1984). Estima-se a ocorrência de 12 mil casos, tendo sido isolados dois sorotipos dos vírus no curso do evento: DEN-1 e o DEN-4. A propagação viral, para o resto do país, não se deu a partir desse episódio, pelo fato do mesmo ter sido rapidamente controlado.

A Dengue só reapareceu no Brasil cinco anos depois, na cidade de Nova Iguaçu (Rio de Janeiro), tendo sido identificado o DEN-1. A partir daí, a virose disseminou-se para outras cidades vizinhas, inclusive Niterói e Rio de Janeiro. Foram notificados 93910 casos, entre abril de 1986 e julho de 1987. Figueiredo (1991) estimou, através de um inquérito sorológico em escolares, que a infecção atingiu mais de um milhão de indivíduos no Rio de Janeiro.

De julho de 1987 até meados de 1990, a doença permaneceu endêmica no Rio de Janeiro, quando nova epidemia de grandes proporções de Dengue Clássica ocorreu em virtude da introdução do vírus tipo 2 . Em 1991, foram notificados 1316 casos graves, dos quais 150 confirmados como de Dengue Hemorrágica. Em 1995, voltou-se a registrar casos de Dengue Hemorrágica no Rio de Janeiro, com 105 notificacões e dois óbitos, além de 26563 de Dengue Clássica (MS/FNS, 1995a).

Em 1986, casos de Dengue foram ainda observados em Alagoas e Ceará, onde foram notificados, respectivamente, 12608 e 26932 casos. No ano seguinte, houve epidemias em Pernambuco (2118 notificaçôes), na Bahia (em Ipupiara, pequena cidade do interior, com 623 casos) e em Minas Gerais (na cidade de Pirapetinga, com 527 notificações).

Após estas primeiras epidemias, o vírus da dengue propagou-se rapidamente por outras áreas do território brasileiro e, até meados de 1996, sua transmissão já havia sido registrada em 638 municípios de 18 Unidades Federadas (MS/FNS, 1996). Cabe destacar a epidemia de 1994, no Ceará, com 47221 notificações, registro de 185 casos suspeitos de Dengue Hemorrágica, com 25 confirmações, e 12 óbitos (MS/FNS, 1995a). O Quadro 1 apresenta um sumário dos casos de dengue no Brasil acumulados desde 1986, por Unidade Federada e sorotipos circulantes (MS/FNS, 1996).

Os últimos casos de Febre Amarela Urbana no Brasil foram registrados em Sena Ma- 
dureira (Acre), em 1942. Entretanto, o ciclo silvestre se mantém em extensas áreas florestais nas regiōes Norte, Centro Oeste e Nordeste (restrita ao oeste do Maranhão), onde o vírus amarílico circula entre primatas nãohumanos. Surtos esporádicos ou casos isolados ocorrem no homem, afetando madeireiros, agricultores, caçadores, pescadores e outros indivíduos que mantêm contato com a mata da área enzoótica (Amaral, 1983; Marques, 1985). Nos últimos anos, o número de casos variou de 2 a 66, respectivamente, em 1990 e 1993. Entre 1982 e 1994, a taxa de letalidade média foi de $55,2 \%$, sendo de $100 \%$, em 1983 , e de $27,3 \%$, em 1993 (MS/FNS, 1995b).

O Programa de Controle de Febre Amarela vem trabalhando guiado pela perspectiva de impedir a sua reurbanização. Até 1994, a vacinaçào antiamarílica era feita apenas nos habitantes da zona enzoótica e em viajantes que se dirigiam a estas regiōes. Com o avanço da infestação do Aedes aegrpti para áreas próximas a zona enzoótica, essa vacina tem sido aplicada, rotineiramente, na população de todos os municípios, a partir de um ano de idade. Face à rapidez dos deslocamentos humanos, através dos meios de transportes atuais, tem-se discutido a necessidade de ampliar a cobertura vacinal para outros estados brasileiros, já que existe a possibilidade de introdução do vírus amarílico em qualquer local infestado pelo Aedes aegupti, com risco de ocorrência cle epidemias de Febre Amarela Urbana (CNS/MS, 1995; MS, 1996). Pelas suas inter-relações, essa questão tem sido objeto de interesse nas discussões acerca da Dengue e da erradicação do Aedes aegypti.

\section{Controle da Dengue nas Américas e no Brasil}

Como já visto, o Brasil e vários outros países americanos adotaram com sucesso a estratégia de erradicação do Aedes aegypti em 1948, conseguindo-se eliminar a Febre Amarela Urbana e impedir a circulação dos vírus da dengue ao longo de muitas décadas. A OPAS, até 1982 , reiterava a política de erradicação para o continente. Em 1985, foi oficialmente alterada a estratégia de erradicação, oferecendo-se aos países a opçào pelo controle ou pela erradicação (OPAS, 1985). O Brasil, apesar da resistência da área técnica

Quadro 1 - Número de Municípios com Aedes aegypti e com Transmissão de Dengue,

\begin{tabular}{|c|c|c|c|c|}
\hline Estados & $\begin{array}{l}\mathrm{N}^{\circ} \text { de Municípios } \\
\text { com Aedes Aegypti }\end{array}$ & $\begin{array}{c}\mathrm{N}^{\circ} \mathrm{de} \\
\text { Municípios com } \\
\text { Dengue }\end{array}$ & $\begin{array}{c}\text { Sorotipo } \\
\text { circulante }\end{array}$ & $\begin{array}{l}N^{\circ} \text { de casos } \\
\text { notificados }\end{array}$ \\
\hline 01. Alagoas & 54 & 8 & DEN II & 794 \\
\hline 02. Bahia & 149 & 119 & DEN II & 34.507 \\
\hline 03 Ceará & 113 & 12 & DEN II & 1.991 \\
\hline 04. Espírito Santo & 19 & 16 & DEN II & 995 \\
\hline 05. Goiás & 153 & 41 & DEN II & 8.191 \\
\hline 06. Rio G. Norte & 46 & 14 & DEN II & 5.181 \\
\hline 07. Rio de Janeiro & 49 & 36 & DEN I e II & 26563 \\
\hline 08. Mato Grosso & 63 & 34 & DEN I e II & 11.628 \\
\hline 09. Mato G. do Sul & 73 & 53 & DEN I & 5.115 \\
\hline 10. Pernambuco & 42 & 20 & DEN I e II & 9295 \\
\hline 11. Paraná & 259 & 112 & DEN I & 3.116 \\
\hline 12. Piauí & 46 & 10 & DEN I & 3.260 \\
\hline 13. Minas Gerais & 126 & 16 & DEN I e II & 2.665 \\
\hline 14. São Paulo & 416 & 97 & DENI & 4.888 \\
\hline 15. Tocantins & 67 & 22 & DEN I & 3.193 \\
\hline 16. Paraíba & 49 & 3 & DEN II & 1.701 \\
\hline 17. Pará & 6 & 2 & DEN I & 28 \\
\hline 18. Maranhão & 24 & 23 & DEN I e 11 & 1776 \\
\hline Total & 1.754 & 638 & & 124.887 \\
\hline
\end{tabular}

Fonte: MS/FNS/DEOPE/CCDTV/GT-FAD

dos órgãos responsáveis pela erradicação (Amaral, 1982; Marques, 1985), também modificou a sua estratégia, criando o Programa de Controle de Dengue e Febre Amarela.

Nos últimos onze anos, as experiências de controle nas Américas mostram que esse é um objetivo possível de ser alcançado, porém difícil de ser sustentado por longos períodos de tempo, em parte, devido, às modificações climáticas sazonais que ocorrem em grandes áreas da América Tropical, pois em 
determinadas épocas do ano a umidade e a temperatura favorecem consideravelmente a proliferação do Aedes aegvpti. Isto significa que os recursos e esforços dispendidos nas estratégias de controle, por não lograrem a completa eliminação do Aedes aegupti nas suas várias formas evolutivas são, em parte, desperdiçados, com a rápida elevação dos índices de infestação do Aedes aegvpti. A isto se somam as descontinuidades no suprimento de recursos a tais programas, prática comum com relaçào às intervenções no campo social nos vários países do continente. É importante ressaltar, no entanto, que em algumas áreas as estratégias de controle conseguem diminuir a infestação para níveis que impedem a circulação viral. Deve-se observar que as atividacles desenvolvidas em tais áreas têm caráter diferenciado, com metodologias e intensidade que as aproximam das campanhas tradicionais de erradicação.

A semelhança entre a gravidade da situação epiclemiológica, em diferentes momentos, do Sudeste Asiático, das Américas e do Brasil está sumarizada no Quadro 2. Em nos- so continente, os acontecimentos relacionados à Dengue vêm ocorrendo com intervalos de aproximadamente vinte anos, quando comparados aos eventos registrados no Sudeste Asiático. Os esforços feitos por muitos dos países americanos, ao perseguirem a meta de erradicação do Aedes aegypti impulsionados pela possibilidade de reurbanização da Febre Amarela, dificultaram também a circulação dos vírus da Dengue por um longo período, justificando essa diferença de tempo observada nas histórias epidemiológicas da Dengue nos dois continentes. No âmbito desta perspectiva podemos projetar para o futuro do continente americano a possível continuidade das epidemias, com o aumento gradativo ou súbito das formas severas da doença.

Nessa linha de preocupação, o Consetho Nacional de Saúde, após análise da situação epidemiológica nacional e do Plano de Intensificação das Ações de Controle da Dengue da FNS (MS/FNS, 1995b), a partir de proposta da representante da Sociedade Brasileira para o Progresso da Ciência (SBPC)/ Associação Brasileira de Saúde Coletiva

Quadro 2 - Semelhança na Seqüência de Fatos que Causam Febre Hemorrágica da Dengue (FHD), no Sudeste Asiático e nas Américas (adaptado de Gluber, 1987).

\begin{tabular}{|l|c|c|c|}
\hline \multicolumn{1}{|c|}{ Fatos } & Sudeste Asiático & Américas * & Brasil ** \\
\hline $\begin{array}{l}\text { Aumento da distribuição e } \\
\text { densidade do Aedes } \\
\text { tegypti }\end{array}$ & $\begin{array}{c}\text { Durante e depois da } \\
\text { II Guerra Mundial } \\
1940-1970\end{array}$ & $\begin{array}{c}\text { Depois do insucesso do } \\
\text { programa de erradicação } \\
1970-1990\end{array}$ & $\begin{array}{c}\text { Apos a reintrodução do } \\
\text { Aedes aegypti em 1976 } \\
1976-1996\end{array}$ \\
\hline $\begin{array}{l}\text { Aumento da transmissão } \\
\text { do dengue }\end{array}$ & $1950-1970$ & $1970-1990$ & $1982-1996$ \\
\hline $\begin{array}{l}\text { Vários sorotipos de dengue } \\
\text { confirmados }\end{array}$ & $1950-1970$ & $1970-1990$ & $1982-1996$ \\
\hline $\begin{array}{l}\text { Aumento da frequiência de } \\
\text { epidemias }\end{array}$ & $1950-1970$ & $1970-1990$ & $1986-1996$ \\
\hline $\begin{array}{l}\text { Casos esporádicos da FHD } \\
\text { confirmados }\end{array}$ & $1950-1970$ & $1970-1990$ & $1991-1996$ \\
\hline $\begin{array}{l}\text { Primeira epidemia da FHD } \\
\text { Diversas epidemias da } \\
\text { FHD com centenas de } \\
\text { milhares de casos } \\
\text { notificados e milhares de } \\
\text { óbitos }\end{array}$ & $\begin{array}{l}1950-1970 \\
1960-1980 \\
1980\end{array}$ & $\begin{array}{c}\text { Milhares de casos e } \\
\text { centenas de óbitos }\end{array}$ & $\begin{array}{c}\text { Risco de graves } \\
\text { epidemias da FHD }\end{array}$ \\
\hline
\end{tabular}

Fonte: Martinez Torres, E. (1990) - Dengue Hemorrág 'ca em Crianças. Havana: Editora José Martí.

* Acrescentada a situação das Américas 1990 -1996. * * Acrescentada a situação do Brasil em todo o período 
(ABRASCO), criou uma Comissão Técnica (CNS, 1995) com a tarefa de examinar a possibilidade de transformar a intensificação do controle em um projeto de erradicação do Aedes aegypti. Esta ação inédita do Conselho estimulou a mobilização de setores da comunidade científica brasileira vinculados à ABRASCO, Sociedade Brasileira de Medicina Tropical e Sociedade Brasileira de Parasitologia. A discussão tem se ampliado, incluindo hoje outros setores da sociedade brasileira.

Neste sentido, em novembro de 1995, em Brasília, realizou-se o Seminário "Erradicação do Aedes aegypti: um desafio para as Américas", organizado pelo Conselho Nacional de Saúde e Ministério da Saúde, por recomendação da Comissão Técnica (CNS), tendo como principal objetivo ampliar a discussão e ouvir a opinião da comunidade acadêmica e científica. Discutiu-se a viabilidade, factibilidade e oportunidade do Brasil elaborar e implantar um plano de erradicação do vetor da Dengue. A Comissão Técnica apresentou, nesse Seminário, um documento para discussão (MS/ CNS, 1995) que pesava os argumentos favoráveis e desfavoráveis à idéia de erradicação e apontava os princípios e diretrizes técnicopolíticas para a construção de um projeto de erradicação para o país: contar com a participação da sociedade; fortalecer a descentralização, segundo princípios e diretrizes do SUS, e contribuir para a melhoria da qualidade de vida das populações urbanas. A maior parte dos seus 120 participantes entenderam, após intensas discussões, que o país deveria elaborar um programa de erradicação do Aedes aegypti e buscar apoio dos outros países americanos no sentido desta estratégia vir a ser adotada como uma estratégia continental unificada.

Com esse respaldo, o CNS/MS intensificou os trabalhos da comissão técnica e ampliou o número de técnicos e pesquisadores envolvidos no processo, culminando na elaboração do Plano Diretor de Erradicação do
Aedes aegypti (MS, 1996) que teve a sua aprovação e regulamentação definidas pelo Presidente da República e 16 Ministros de Estado, através do Decreto $n^{\circ} 1934$, de 18 de junho de 1996.

No plano externo, o Conselho Diretor da OPAS criou um Grupo Técnico Assessor (OPAS, 1995c), com o objetivo de examinar a questão da erradicação do Aedes aegypti nas Américas. Este grupo, reunido pela primeira vez em abril de 1996, concluiu pela factibilidade, oportunidade e conveniência da erradicação (OPAS,1996). No plano interno, tem-se intensificado a discussão do Plano Diretor com amplos segmentos da sociedade, conselhos de saúde, além de técnicos e profissionais da área da saúde. O Plano de Erradicação, em nível nacional, tem seu início previsto para o início de 1997, enquanto Projetos Pilotos estão sendo elaborados para implantação em curto período de tempo, visando construir e acumular experiências com relação às estratégias propostas.

\section{Aedes aegypti: Erradicação?}

Ao longo do tempo, a Saúde Pública vem desenvolvendo conhecimentos e experiências voltados para a prevenção de doenças e agravos específicos que, idealmente, são aplicados de acordo com o desenvolvimento científico e tecnológico disponíveis em cada ocasião. Payne (1967) define vários estágios no processo de prevenção. O primeiro nível é a prevenção aplicada ao indivíduo. O segundo nível é o controle aplicado a uma comunidade, seja ela pequena ou grande; nesse patamar aceita-se a ocorrência da doença, desde que com freqüência e/ou gravidade reduzida, segundo parâmetros que variam com a natureza do problema de saúde e com a atitude da comunidade. O terceiro patamar é a eliminação do agravo: neste estágio, seu efeito no homem é reduzido de modo a não mais se 
constituir em um problema de saúde pública, pois a doença clínica está ausente ou é extremamente rara, embora o agente causal quími$\mathrm{co}$, físico ou biológico não tenha sido eliminado. O quarto e último nível é a erradicação. Esta palavra, derivada da raiz latina radix, significa literalmente "arrancando-se pela raiz". Trata-se de um processo mais completo que o da eliminação, pois pressupôe a extinção tanto da doença clínica como de sua causa. Constitui o último estágio de resolução do problema, e o mais difícil de ser alcançado mas, sem dúvida, o mais efetivo e eficaz.

Os parâmetros técnicos que têm sido utilizados mais freqüentemente na priorização de doenças e agravos a serem tomados como objetos de intervenções são a magnitude, a transcendência, a vulnerabilidade e o custo (Teixeira \& Risi, 1995). Mensura-se a magnitude através da prevalência e incidência; a transcendência, pela gravidade e pelo valor social, ou seja, pelo impacto atual ou potencial e suas repercussões no desenvolvimento sócio-econômico; e a vulnerabilidade pela disponibilidade de recursos tecnológicos para a prevenção e controle. A análise desses parâmetros, bem como a sua compatibilização com o volume de recursos necessários e disponíveis definem, em tese, a meta final a ser alcançada pelo programa: prevenção individual, controle, eliminação ou erradicação. Entretanto, no mundo real, observa-se que a concretização das prioridades das ações de saúde resulta, em última instância, de decisões de ordem política, com maior ou menor grau de fundamentação nos conhecimentos técnicos científicos disponíveis. Estas decisões nem sempre expressam os interesses ou necessidades dos grupos sociais atingidos pelo problema em tela.

Por ser a dengue uma doença infecciosa e de transmissão vetorial, e devido à inexistência, até o momento, de uma vacina e de drogas antivirais específicas, a questão da sua prevenção gira em torno de intervenções que limitem a população do Aedes aegypti, po- dendo-se optar pelo controle, eliminação ou erradicação. $O$ controle tem sido definido como o uso integrado e seletivo dos diferentes métodos de combate vetorial de forma eficaz, econômica e segura, de modo a reduzir a população do vetor e a transmissão a níveis aceitáveis (OPAS, 1996b). Esses níveis não têm sido definidos quantitativamente. As intervenções visando ao controle vêm se baseando em dois conjunto de ações: o combate químico e o manejo ambiental (OPAS, 1995b, 1996). O combate químico permite atuar nas formas larvárias ou adultas do vetor. As larvas são eliminadas em seu habitat (coleções de água acumuladas), através do uso de larvicidas de poder residual, enquanto as formas aladas o são através da pulverização do meio ambiente com inseticidas piretróides ou organo-fosforados a "ultra-baixo volume" (UBV). Têm sido feitas tentativas, com perspectivas promissoras, de utilização de métodos biológicos de controle de larvas (OPAS, 1995b). O manejo ambiental nos atuais programas de controle tem, em geral, se limitado à destruição de potenciais criadouros no ambiente domiciliar e peri-domiciliar, sem intervir em outros elementos da infra-estrutura urbana (coleta de lixo, suprimento de água etc.) e do modo de vida das populações.

Apesar de vários países das Américas terem sido considerados como "livres" do Aedes aegvpti, em passado recente, a discussão acerca das dificuldades ou mesmo da impossibilidade de se erradicar uma espécie biológica de uma extensa área geográfica permanece viva. Entretanto, o Aedes aegypti não é autóctone desse hemisfério, mas sim do continente Africano, tendo se adaptado em nosso meio a ambiente estritamente humano, no domicílio e peridomicílio (Amaral, 1983). Deste modo, por não ser encontrado em nicho natural, possibilita uma maior eficácia das medidas de combate aplicadas, facilitando a sua erradicação.

O atual quadro de ocorrência da Dengue no Brasil configura uma situação que poderí- 
amos considerar de elevada magnitude, devido às freqüentes e explosivas epidemias em importantes centros urbanos. Por sua vez, a Dengue Hemorrágica e a Síndrome do Choque da Dengue já estão presentes em algumas áreas, associadas a uma alta letalidade no estado do Ceará (MS/FNS, 1995a). A possibilidade de eclosão de epidemias "explosivas" dessa forma da doença torna sua transcendência inquestionável. Por outro lado, a incidência da Dengue Clássica tem sido muito elevada em várias capitais brasileiras, com repercussões sobre o absenteísmo na esfera do trabalho e da frequiência às escolas, pois em grande parte dos indivíduos acometidos impede o desempenho das atividades habituais, por vários dias.

A vulnerabilidade da dengue às ações preventivas se restringe ao impacto das ações de combate ao mosquito transmissor, o Aedes aegypti. É neste contexto que se deve situar a discussão sobre as alternativas: controle ou erradicação?

Argumentos favoráveis e desfavoráveis com relação a ambas alternativas têm sido apresentados. Alguns estão sendo superados, obtendo-se em alguns pontos consensos, outros vêm causando dificuldades ou mesmo determinando impasses no campo das idéias e das práticas a serem estabelecidas. Os principais fatores que têm sido mencionados como impeditivos para o alcance da meta de erradicação incluem: o fato do vetor já se encontrar disperso em quase todo o continente e em grande área do território brasileiro; a complexidade da malha dos grandes centros urbanos; as dificuldades dos agentes sanitários e das ações de saúde em atingirem as áreas de difícil acesso, como as favelas; e a inexistência de um pacto continental de erradicação. Os defensores do controle argumentam ainda que este só tem falhado em virtude das dificuldades administrativas e operacionais, e não por ser tecnicamente incorreto. Por outro lado, teme-se que a opção por uma estratégia de erradicação possa favorecer a retomada do modelo campanhista, no estilo de operação militar com comando único central, e que este modelo vertical se contraponha às diretrizes do Sistema Único de Saúde (SUS), constituindo-se em um novo obstáculo ao seu desenvolvimento.

Em contrapartida, vários têm sido os argumentos dos defensores da erradicação. O primeiro relaciona-se à necessidade de uma mudança de estratégia face à gravidade da situação epidemiológica do Brasil e das Américas, com risco de ocorrência de grandes epidemias de Dengue Hemorrágica e de Febre Amarela Urbana, uma vez que, ao longo dos últimos onze anos (período de existência dos programas de controle), não têm sido registradas vitórias contra o avanço da dengue e do vetor. Menciona-se também o fato do Brasil e outros países americanos já terem erradicado o Aedes aegvpti, o que aponta para a viabilidade de se repetir com êxito esta proposta, e que os meios de comunicação, informação e educação evoluíram significativamente nos últimos anos, possibilitando o enfrentamento das dificuldades relacionadas à complexidade da malha urbana e ao desenvolvimento dos trabalhos em áreas de difícil acesso. Apontam ainda para a possibilidade de construção de um consenso entre os países do continente americano em torno de uma proposta de erradicação, citando o exemplo recente da poliomielite, cuja erradicação foi conquistada a partir de um pacto continental e ações efetivas e contínuas, cobrindo toda a extensào territorial dos países do hemisfério.

A reflexão sobre a epidemiologia da Dengue e seus determinantes recoloca o problema em uma esfera político-social mais abrangente, pois a reinfestação pelo Aedes aegypti do continente e, particularmente, do Brasil tem sido favorecida pelas péssimas condições sanitárias dos centros urbanos, 
fruto da ocupação desordenada dos espaços, e dos insuficientes investimentos em saneamento básico. A despeito do desenvolvimento industrial e urbano, as atuais condiçòes de higiene das grandes cidacles brasileiras se assemelham em muitos aspectos àquelas do início do século quando ocorreram as grandes epidemias de Febre Amarela. Os aglomerados populacionais, sob a forma de favelas ou de habitações em palafitas, onde é rara ou inexistente a coleta de resíduos sólidos; o acúmulo desses resíduos dentro e fora dos domicílios; os deficientes sistemas de abastecimento de água, levando ao seu armazenamento em condições propícias ao desenvolvimento das formas evolutivas do vetor, são fatos que devem ser considerados nesse debate atual, pois enfatizam a complexidade e a importância da determinação social na ocorrência da Dengue. A inexistência de uma vacina eficaz e de tratamento específico, diferencia o problema da erradicação da Dengue de outras doenças anteriormente erradicadas. A necessidade de centrar o processo de eliminação da circulação viral no combate ao vetor implica a impossibilidade de dissociar o processo de prevenção de ações sobre os fatores condicionantes e determinantes, o que significa intervenções que melhorem a qualidade de vida das populações.

A simples proposta de controle vetorial tem se baseado fundamentalmente no combate químico, com intervenções restritas na área ambiental, organizadas ainda segundo um modelo vertical e, portanto, sem nenhum poder de motivação da sociedade de um modo geral e, mesmo, das populações diretamente envolvidas. As descontinuidades administrativas e operacionais desses programas não são mais do que reflexos da sua baixa capacidade de gerar compromissos sociais e da pouca prioridade destas ações no âmbito do sistema político-administrativo.

\section{Considerações Finais}

A construção de um projeto nacional de erradicação, com as características acima apresentadas, traz novos elementos que o tornam defensável, tanto do ponto de vista técnico como político e social, além de se constituir em um experimento para futuras inovações na área da saúde pública no país. Do ponto de vista técnico, ele é inovador por levar em consideração a questão da determinação da doença e apontar para uma estratégia técnico-científica de enfrentamento, não apenas fundamentada em açōes dirigidas à base biológica do problema, mas, principalmente, à sua base ambiental e social. Do ponto de vista político, este é um projeto que nasceu fora da burocracia estatal, na medida em que resulta de uma iniciativa do Conselho Nacional de Saúde que rapidamente mobilizou parcelas significativas da inteligência nacional e da sociedade como um todo. A sua execução trará benefícios sociais de grande monta, pois além da eliminação da circulação dos vírus da Dengue, terá impacto sobre a incidência de doenças associadas à falta de saneamento básico como as diarréias, a leptospirose, a hepatite A e o cólera. O seu desenho impõe um desafio para a saúde pública no continente, pois incorpora a maioria dos princípios e diretrizes que nortearam as reformas sanitárias gestadas dentro dos movimentos populares e de profissionais de saúde: por ser descentralizado, fortalece o processo de municipalização das ações de saúde; exige ampla participação e compromisso social; envolve as três esferas de governo e vários setores da sua organização político-administrativa. Além disso, esse novo modelo de erradicação estimula o desenvolvimento e a aplicação de novos conhecimentos científicos e tecnológicos e, simultaneamente, procura resgatar as experiências anteriores de erradicação e controle, enfatizando 
seus elementos positivos. Por fim, entende que as ações químicas e de saneamento domiciliar e peri-domiciliar são relevantes, porém insuficientes para a "sustentabilidade" dos resultados alcançados, a qual só se dará em função de ações estruturais sobre o espaço urbano em sua globalidade, somadas às iniciativas dos indivíduos no sentido de manter e preservar a qualidade do seu ambiente. A convergência de todas essas ações deverá resultar na melhoria da qualidade de vida das cidades brasileiras e do nível de educação sanitária de suas populações.

Pelo exposto acima, a concepção técnica, política e organizacional do Plano Diretor de Erradicação do Aedes aegypti do Brasil deve ser defendida e a sua implantação acompanhada e avaliada pelos profissionais da área de saúde pública e pela sociedade em geral. Como tem ocorrido com a própria implanta-

\section{Referências bibliográficas}

AMARAL, R. \& TAUIL, L.P. (1983) - Duas ameaças e um mosquito: febre amarela e dengue. A saúde no Brasil I(4)

BRASIL.Ministério da Saúde/Fundação Nacional de Saúde (1995a) - Manual de dengue: vigilância epidemiológica e atençào ao doente. Brasília: DEOPE.

BRASIL.Ministério da Saúde/ Fundação Nacional de Saúde (1995b) - Plano de Intensificação das Açòes de Controle do Dengue. Brasîlia: DEOPE.

BRASIL. Ministério da Saúde/Conselho Nacional de Saúde (1995) - Documento apresentado no Seminário Erradicação do Aedes aegypti: um desafio para as Américas. Diretrizes técnico-políticas para a construção de um projeto de erradicação do Aedes aegypti do Brasil. Brasília, mimeo.

BRASIL. Ministério da Saúde/Fundação Nacional de Saúde (1996) - Documento apresentado na "Reunión del grupo tecnico asesor para el estudio de la factibilidade, oportunidad y conveniencia de la erradicación del Aedes aegypti en las Americas. ção do SUS e outras conquistas sociais no país, muitas dificuldades possivelmente surgirão no decorrer desse processo, particularmente no campo político-administrativo. A comunidade científica, os profissionais de saúde e a sociedade em geral devem estar mobilizados para lutar pela sua execução e pela observância das suas diretrizes. Emanado do Conselho Nacional de Saúde, o Plano repõe questões essenciais para o próprio SUS e, mais do que isto, para a própria saúde pública, ao possibilitar a recuperação desta como parte dos grandes movimentos pela melhoria da qualidade do viver. Se as suas eventuais deficiências e insuficiências forem compreendidas como parte do processo de sua construção, e na medida em que sua estrutura democrática e participativa for garantida e a gestação de alternativas estimulada, tais obstáculos poderão ser superados.

Dengue no Brasil: estado atual, estratégias de controle/erradicação, problemas e potenciais soluções. Brasilia, mimeo.

BRASIL. Ministério da Saúde (1996) - Plano Diretor de Erradicação do Aedes aegypti do Brasil. Brasilia, mimeo.

BRÉS, P. (1986) - A Century of Progress in Combating Yellow Fever. Bulletin WHO 64(6):775-786.

CAUSEY, O.R. \& THEILER, M. (1962) - Virus Antibody Survey on Sera of Residents of the Amazon Valley in Brazil. Revista Servicio Español de Salud Puíblica XII(1):91-101.

CDCs (Centers for Disease Control) (1979) Control of Dengue. Vector Topics 2:1-39.

CNS.MS (Conselho Nacional de Saúde/Ministério da Saúde) (1995) - Resolução. n² 160. Brasîlia, mimeo.

COSTA, N.R. (1985) - Lutas urbanas e controle sanitário: origens das políticas de saúde no Brasil. Rio de Janeiro: Vozes.

DONALISIO, M.R. de C. (1995) - O enfrenta- 
mento de epidemias: as estratégias e perspectivas do controle do dengue. Tese de doutorado, UNICAMP, Campinas, mimeo.

EHRENKRANZ, J.N. (1971) - Dengue in Caribbean Countries and the Sourthern United States - Past, Present and Potentials Problems. New England Journal of Medicine 285 (26):1460-1469.

FIGUEIREDO, L.T.M.; CAVALCANTE, S.M.B. \& SIMÕES, M.C. (1991) - Encuesta serológica sobre el dengue entre escolares de Rio de Janeiro, Brasil,1986 y 1987. Boletin de la Oficina Sanitaria Panamericana 111(6): 525-533.

FRANCISCO, N.C. (1983) - Fiebre Hemorrágico por Dengue (FHD), Sudeste Asiático y Pacífico Occidental (Articulo de Revisión - I Parte). Revista del Clube de Medicina Tropical 35:130-135.

FRANCO, O. (1976) - História da febre amarela no Brasil. Rio de Janeiro: Ministério da Saúde/SUCAM.

HALSTEAD, S.B. \& PAPAVANGELOU, G. (1980) - Transmission of Dengue 1 and 2 viruses in Greece in 1928. American Journal of Tropical Hygiene 29(4):635-637.

KOURI, G.P.; GUZMÁN, M.G. \& BRAVO, J. (1986) - Dengue hemorrágico en Cuba. Crónica de una epidemia. Boletin de la Oficina Sanitaria Panamericana 100(3):322-329.

MARQUES, A.C. (1985) - Sobre a viabilidade atual da erradicação do Aedes aegypti no controle a febre amarela do Brasil. Revista Brasileira de Malariologia e Doenças Tropicais 37:47-59.

NELSON, M. (1996) - Programas de dengue e Aedes en las Americas. Brasília: Organización Panamericana de la Salud, mimeo.

OPAS (Organización Panamericana de la Salud) (1942) - La XI Conferencia Sanitaria Panamericana. Resolución CSP 11.11, Pub. 205, 7.

OPAS (Organización Panamericana de la Salud) (1947) - Resolución CD I, Pub. 246, 3.

OPAS (Organización Panamericana de la Salud) (1958) - Resolución CSP 15.35, DO 27, 41.

OPAS (Organización Panamericana de la Salud) (1960) - Resolución CD 12.4, DO 36, 18.

OPAS (Organización Panamericana de la Salud) (1961) - Resolución CD 13.34, DO 41, 39.

OPAS (Organización Panamericana de la Salud) (1963) - Resolución CD 14.13, DO 54, 14.
OPAS (Organización Panamericana de la Salud) (1965) - Resolución CD 16.28, DO 6634.

OPAS (Organización Panamericana de la Salud) (1982) - La XXI Conferencia Sanitaria Panamericana. Resolución CSP 21. R28.

OPAS (Organización Panamericana de la Salud) (1985) - Control and Erradication of Aedes aegypti . Resolution XXVI.

OPAS (Organización Panamericana de la Salud) (1995a) - Alternativas para la $1^{\text {a }}$ prevención y control del dengue hemorragico en los paises de CentroAmerica. CHT/95, 049. Rev 1.

OPAS (Organización Panamericana de la Salud) (1995b) - Dengue y Dengue Hemorrágico en las Americas: guias para su prevención y control. Publicación Científica № 548.

OPAS (Organización Panamericana de la Salud) (1995c) - Enfermedades Infecciosas Nuevas, Emergentes y Reemergentes. Resolución CD38. R12.

OPAS (Organización Panamericana de la Salud) (1996a) - Meeting of the Task Force to Study the Feasibility, Timeliness and Appropriateness of Eradicating Aedes aegypti from the Americas. PAHO/ HCP/HCT/96.068.FIOCRUZ, Rio de Janeiro, Brasil, mimeo.

OPAS (Organización Panamericana de la Salud) (1996b) - Taller para la promoción del combate al Aedes aegypti/Dengue. OPS/HCP/HCT/96.066, Asunción, Paraguai, mimeo.

OSANAI, C.H. (1984) - A epidemia de Dengue em Boa Vista, território Federal de Roraima, 19811982. Dissertação de Mestrado, ENSP-FIOCRUZ, Rio de Janeiro, mimeo.

PAPAVANGELOU, G. \& HALSTEAD, S.B. (1977) - Infections with Dengue Viruses in Greece in the $20^{\text {th }}$ century. Did the Dengue Hemorragic Fever Occur in the 1928 Epidemic ? American Journal of Tropical Hygiene 80:40-51.

PAYNE, A.M.-M. (1967) - The Basis of Preventive Measures. In: Clark, D.W. \& Macmahon, B. (eds.) Preventive medicine. Boston: Little, Brown and Company.

PINHEIRO, F.P. (1996) - Los programas de erradicacion y de control del Aedes aegypti en las Americas. OPS/HCP/HCT/96.63.

RODRÍGUEZ EXPOSITO, C. (1971) - Carlos J. 
Finlay - Obras Completas T. V. La Habana: Academia de Ciencias de Cuba.

RUANET, P.L.; FRANCO, O. \& SANTOS, A. (1940)

- Consideraçòes sôbre a campanba antiestegômica no Nordeste do Brasil. Recife: Serviço Nacional de Febre Amarela.

SOARES, P. (1928) - Etiologia Symptomatologia

e Prophylaxia da dengue - A epidemia do
Aviso francês "Antarès" no Porto da Bahia. Arquivo do Hospital de Isolamento em Mont'Serrat, Salvador, Bahia.

TEIXEIRA, M.G. \& RISI, J.B. (1995) - Vigilância Epidemiológica In: Guia de Vigilância Epidemiológica. Brasilia: MS/FNS.

TORRE, M.E. (1990) - Dengue bemorrágico en crianças. La Habana, Cuba: Editorial José Marti. 